\title{
Premature frailty, geriatric conditions and multimorbidity among people experiencing homelessness: a cross-sectional observational study in a London hostel
}

\author{
Raphael Rogans-Watson, Caroline Shulman, Dan Lewer, Megan Armstrong and \\ Briony Hudson
}

\begin{abstract}
Purpose - The purpose of this paper is to assess frailty, geriatric conditions and multimorbidity in people experiencing homelessness (PEH) using holistic evaluations based on comprehensive geriatric assessment (CGA) and draw comparisons with general population survey data.

Design/methodology/approach - Cross-sectional observational study conducted in a London-based hostel for single PEH over 30 years old in March-April 2019. The participants and key workers completed health-related questionnaires, and geriatric conditions were identified using standardised assessments. Frailty was defined according to five criteria in Fried's phenotype model and multimorbidity as the presence of two or more long-term conditions (LTCS). Comparisons with the general population were made using data from the English Longitudinal Study of Ageing and the Health Survey for England.

Findings - A total of 33 people participated with a mean age of 55.7years (range 38-74). Frailty was identified in 55\% and pre-frailty in 39\%. Participants met an average of $2.6 / 5$ frailty criteria, comparable to 89 -year-olds in the general population. The most common geriatric conditions were: falls (in 61\%), visual impairment (61\%), low grip strength (61\%), mobility impairment (52\%) and cognitive impairment (45\%). All participants had multimorbidity. The average of 7.2 LTCs (range 2-14) per study participant far exceeds the average for even the oldest people in the general population.

Originality/value - To the best of authors' knowledge, this is the first UK-based study measuring frailty and geriatric conditions in PEH and the first anywhere to do so within a CGA-type evaluation. It also demonstrates the feasibility of conducting holistic evaluations in this setting, which may be used clinically to improve the health outcomes for PEH.
\end{abstract}

Keywords Ageing, Homelessness, Multimorbidity, Frailty, Geriatric conditions, Inclusion health

Paper type Research paper

\section{Introduction}

Homelessness is associated with extremely poor health outcomes, and cohort studies report mortality rates of 3-6 times the general population (Fitzpatrick et al., 2013; Queen et al., 2017; Bowen et al., 2019; Lewer et al., 2019). The number of people experiencing homelessness $(\mathrm{PEH})$ in the UK (which includes sleeping on the streets, in insecure housing, temporary accommodation or hostels) has been steadily rising throughout the past decade (Bramley, 2017; Office for National Statistics, 2019). The number of older people in this situation is also increasing, but their health and social needs and the impact of homelessness on the ageing process are inadequately understood (Gelberg et al., 1990; Centre for Policy on Ageing, 2017). Practitioners working in the field of inclusion health anecdotally report signs of premature ageing among those who have experienced multiple
(Information about the authors can be found at the end of this article.)

Received 12 May 2020 Revised 24 June 2020 Accepted 5 July 2020

(c) Raphael Rogans-Watson, Caroline Shulman, Dan Lewer, Megan Armstrong and Briony Hudson. Published by Emerald Publishing Limited. This article is published under the Creative Commons Attribution (CC BY 4.0) licence. Anyone may reproduce, distribute, translate and create derivative works of this article (for both commercial and non-commercial purposes), subject to full attribution to the original publication and authors. The full terms of this licence may be seen at http://creativecommons.org/licences/by/4.0/ legalcode.

The authors would like to thank all the hostel residents and staff for their involvement, Fenella Jolly and Kendra Schneller of the local Health Inclusion Team and Nigel Hewett and Alex Bax from Pathway for their support with the study. Pathway (Charity Registration Number 1138741) is the UK's leading homeless health-care charity. 
exclusion and homelessness and refer to those who are "old before their time", but a paucity of published data exists.

Frailty is a health state related to ageing, characterised by loss of in-built reserves across multiple body systems and associated with vulnerability to adverse outcomes (Fried et al., 2001; British Geriatrics Society, 2015). Four studies assessed frailty among PEH in the USA using a variety of definitions, finding more than half of participants were frail (Salem et al., 2013, 2014; Hadenfeldt et al., 2017; Salem et al., 2019), and studies in the USA and Ireland reported premature onset of geriatric conditions such as cognitive and functional impairments (Brown et al., 2012, 2017; Ni Cheallaigh and Sears, 2018). In the UK, people living in hostels often have very complex health and social care needs (Shulman et al., 2018; Manthorpe et al., 2019). They tend to be supported by non-clinical hostel staff with variable clinical support from primary care. However, multiple barriers in accessing primary care along with challenges to proactive care planning and limited functional support in the hostel contribute to continuing poor health for many people (Crane and Joly, 2014; Bradley, 2018; Eavis, 2018; Martineau et al., 2019). There is good evidence that multi-disciplinary holistic interventions such as comprehensive geriatric assessment (CGA) can reduce functional dependence and improve outcomes for people living with frailty in the general population (Turner and Clegg, 2014; British Geriatrics Society, 2015; Ellis et al., 2017). CGA is a process of care comprising a multi-dimensional holistic assessment with personalised care plans and patient-centred interventions. It is commonly used in geriatric medicine and has been shown to improve independence, reduce hospital admissions and even reverse the progression of frailty (Turner and Clegg, 2014; Ellis et al., 2017). A CGA-type process to identify and manage frailty and geriatric conditions for people living in hostels could enable services to better identify and address their needs.

The purpose of this study is to determine the extent of frailty and geriatric conditions in people living in a hostel, drawing comparisons with general population surveys. The study also tests different frailty scales and the feasibility of conducting a CGA-type holistic evaluation in this setting. To our knowledge, this is the first study of frailty or geriatric conditions among PEH in the UK.

\section{Methods}

\section{Study design and procedure}

This cross-sectional observational study involved a 60 minute interview with each participant conducted by a geriatric medicine registrar including a questionnaire modelled on a typical CGA and assessments for frailty and geriatric conditions (detailed further). Some interviews were conducted over several sessions, depending on participants' preferences. Hostel key workers also completed questionnaires to provide collateral information about health conditions and functional impairments. At the end of the interview, each participant was compensated with a $£ 10$ supermarket voucher.

\section{Setting and participants}

The study took place in London, UK, in a 42-bed hostel for single homeless people above 30 years old, who have complex needs including mental health difficulties, behavioural issues and/or substance misuse. Residents must have a local connection to the borough and the hostel is considered suitable for residents with relatively high needs and includes a number of wheelchair accessible rooms with accessible bathroom facilities. Similar to other hostels in the borough, support for residents is primarily provided by non-clinical key workers but also includes twice-weekly site visits by a nurse and a general practitioner (GP). If residents require social care (such as for personal care or support with medications), an application must be made to the local authority. 
Information sheets were distributed in February 2019. All residents were invited to participate between 4 March 2019 and 23 April 2019. Participants and key workers provided written informed consent. Exclusion criteria were inability to give informed consent or a significant communication barrier. Any health concerns identified during the study were referred to the GP or nurse providing twice-weekly clinics in the hostel, with participants' consent. The study was approved by the University College London Research Ethics Committee [ID: 6202/003].

\section{Variables}

Frailty

Frailty was assessed using the five criteria in Fried's phenotype model:

- weakness;

- slow walking speed;

- unintentional weight loss;

- exhaustion; and

- low physical activity (Fried et al., 2001).

Frailty is defined as the presence of three or more criteria. Presence of one or two criteria is classified as "pre-frail" and zero as "not frail". Assessments and diagnostic criteria (Table A1) were based on methods used in the English Longitudinal Study of Ageing (ELSA), enabling comparison to population data (Banks et al., 2019). Frailty was also assessed using the Edmonton frail scale (Rolfson et al., 2006) and the Rockwood frailty scale (Rockwood et al., 2005), but without comparable population data.

\section{Geriatric conditions}

Common geriatric conditions were identified using the following tools:

- Cognitive impairment - Rowland universal dementia assessment scale (RUDAS) (Storey et al., 2004).

- Urinary incontinence - International Consultation on Incontinence Questionnaire (ISIQUI) (Avery et al., 2004).

- Falls - direct questions regarding the past 12 months.

- Osteoporotic fracture risk - Sheffield University FRAX tool (Centre for Metabolic Bone Diseases, 2018).

- Malnutrition risk - Malnutrition Universal Screening Tool (MUST) (British Association for Parenteral and Enteral Nutrition, 2003)

- Orthostatic hypotension-Blood pressure readings at 1 and 3 min after standing.

- Visual impairment - Snellen chart assessment (self-reported assessment accepted in three participants unable to complete this because of mobility impairment).

- Low grip strength - using a dynamometer in the dominant hand, with the maximum of three attempts taken.

- Functional impairment (reported by participants and key workers) using-modified Katz index (Shelkey and Wallace, 2002) for five activities of daily living (ADLs): bathing, dressing, toileting, transferring and feeding; brief instrumental functional scale (BIFS) (Sullivan et al., 2001) for six instrumental activities of daily living (IADLs): taking transport, managing medications, money and appointments, writing an email and filling in an application form. Preparing a meal was not included as the hostel provided food. 
- Social isolation - direct questions regarding contact with family or friends.

- Mobility impairment, balance impairment and hearing impairment-direct questions.

\section{Multimorbidity}

Health conditions were recorded from participant and key worker questionnaires and grouped into 39 codes for long-term conditions (LTCs) used in the Health Survey for England (HSE) (Marshall and Higgins, 2012). The 39 LTCs are listed in Table A2. Multimorbidity is defined as the presence of two or more LTCs in one person. The participants were also asked about history of traumatic head injury and assessed for depression using the patient health questionnaire (PHQ-9) (Kroenke et al., 2001).

\section{Analysis}

Analysis was conducted using SPSS version 25 and R version 3.5.1 (IBM Corp, 2017; R Core Team, 2018). We first described the characteristics of the participants and prevalence of each condition. We then compared Fried frailty phenotype scores and number of LTCs in the participants with the general population. We calculated frailty phenotype scores for ELSA participants using data from 2006-2011 (Banks et al., 2019) following methods used in a previous study (Gale et al., 2014). We then predicted the mean scores by single-year-of-age using a Poisson regression model with polynomial terms of age (up to age cubed) as the independent variables and the frailty score as the dependent variable. Means were predicted for ages 60-89 years old because ELSA does not include younger participants. We used the same method to estimate age-related trends in number of LTCs for people aged 35-89 in the general population, using data from the HSE 2015 (Marshall and Higgins, 2012).

\section{Results}

\section{Participant characteristics}

Of the 42 residents, 2 were ineligible (one because of language barrier and another because of severe hearing impairment) and 7 declined, leaving a sample of 33. Four key workers completed collateral questionnaires for all participants. Table 1 displays participant characteristics. The mean age was 55.7 years $(S D=10.0)$ and $91 \%$ were identified as male. Of those dependent on alcohol or drugs $(n=31 / 33)$, seven were engaged with a drug and alcohol service.

\section{Frailty, geriatric conditions and multimorbidity}

Table 2 displays prevalence of frailty, geriatric conditions and multimorbidity. In all, 55\% ( $n=18 /$ 33) of participants were frail, meeting $\geq 3$ criteria in Fried's phenotype model and $39 \%(n=13$ / 33) had pre-frailty. Frail participants had a mean age of 56 years $(\mathrm{SD}=11$, range 38-73). Figure 1 shows number of frailty criteria met by each participant and the mean in the general population, plotted against age. The participants met a mean of 2.6 out of 5 criteria, comparable to the mean for 89-year-olds in the general population. Frailty was identified in 55\% of participants using the Edmonton frail scale and $48 \%$ using the Rockwood frailty scale (Table A3).

All geriatric conditions except hearing impairment were identified in at least $30 \%$ of participants. The most common were falls, visual impairment and low grip strength in $61 \%$; mobility impairment in 52\%; and cognitive impairment in 45\% (only 3 out of 15 had a charted diagnosis). Urinary incontinence was identified in 30\% and 39\% were at high risk of malnutrition (MUST score of $\geq 2$ ), but only $12 \%$ had calorie supplementation. Social isolation was common, with $55 \%$ having no family contact and $30 \%$ with no friends or any family contact. The probability of osteoporotic fracture was high in $32 \%(n=10 / 31$ : we were unable to calculate probability for two participants because of incomplete data); none had bisphosphonate prescribed. 
n (\% of 33 participants) unless stated otherwise

\begin{tabular}{|c|c|c|}
\hline Age & $\begin{array}{l}\text { Mean (SD), years } \\
\text { Range, years } \\
35-44 \\
45-54 \\
55-64 \\
65-74\end{array}$ & $\begin{array}{c}55.7(10.0) \\
38-74 \\
5(15) \\
9(27) \\
14(42) \\
5(15)\end{array}$ \\
\hline Sex & $\begin{array}{l}\text { Male } \\
\text { Female }\end{array}$ & $\begin{array}{c}30(91) \\
3(9)\end{array}$ \\
\hline Birth place & $\begin{array}{l}\text { The UK } \\
\text { Overseas }\end{array}$ & $\begin{array}{r}27(82) \\
6(18)\end{array}$ \\
\hline Age left school & $\begin{array}{l}<16 \text { years } \\
\geq 16 \text { years }\end{array}$ & $\begin{array}{l}15(45) \\
18(55)\end{array}$ \\
\hline Time in this hostel & $\begin{array}{l}<1 \text { year } \\
1-2 \text { years } \\
>2 \text { years }\end{array}$ & $\begin{array}{r}15(45) \\
9(27) \\
9(27)\end{array}$ \\
\hline $\begin{array}{l}\text { Lifetime homelessness } \\
\text { (Cumulative duration, includes vulnerable } \\
\text { housing and hostels) }\end{array}$ & $\begin{array}{l}<7 \text { years } \\
7-13 \text { years } \\
14-23 \text { years } \\
>23 \text { years }\end{array}$ & $\begin{array}{r}8(24) \\
8(24) \\
11(33) \\
6(18)\end{array}$ \\
\hline $\begin{array}{l}\text { Lifetime rough sleeping } \\
\text { (Cumulative duration) }\end{array}$ & $\begin{array}{l}\text { Never } \\
<1 \text { year } \\
1-5 \text { years } \\
>5 \text { years }\end{array}$ & $\begin{array}{r}5(15) \\
11(33) \\
5(15) \\
12(36)\end{array}$ \\
\hline Smoking & $\begin{array}{l}\text { Current } \\
\text { Former } \\
\text { Never }\end{array}$ & $\begin{array}{l}27(82) \\
2(6) \\
4(12)\end{array}$ \\
\hline Alcohol & $\begin{array}{l}\text { Currently dependent } \\
\text { Recurrent hazardous } \\
\text { drinking } \\
\text { Not dependent }\end{array}$ & $\begin{array}{l}24(73) \\
2(6) \\
7(21)\end{array}$ \\
\hline $\begin{array}{l}\text { Class A drug misuse } \\
\text { (Heroin, crack and cocaine) }\end{array}$ & $\begin{array}{l}\text { Current } \\
\text { Former } \\
\text { Never }\end{array}$ & $\begin{array}{r}12(36) \\
8(24) \\
13(39)\end{array}$ \\
\hline
\end{tabular}

Regarding functional impairments, $18 \%$ of participants reported some difficulty or inability to carry out one or more ADL, with key workers reporting 39\% had difficulty with one or more. In all, 94\% of participants (and 91\% of key workers) reported difficulty with one or more IADL. On an average, participants reported difficulty with 3.2 out of 6 IADLs. Full ADL and IADL results from participants and key workers are given in Table A4. Just three participants (9\%) had a package of care for personal care or medication prompting and six (18\%) had a carer cleaning their room.

Multimorbidity was present in all participants, with an average of 7.2 LTCs per person (Table 2). Figure 2 plots participants' number of LTCs against HSE data. All had more LTCs than the mean number for people their age in the general population. In spite of the study sample's average age of 56, every participant had more LTCs than the average for 90 -year olds in the general population. The most common LTCs were: liver 
n (\% of non-missing values)

\begin{tabular}{|c|c|c|}
\hline \multicolumn{3}{|l|}{ Frailty } \\
\hline & Not frail (0 criteria) & $2(6)$ \\
\hline \multirow[t]{2}{*}{ Fried phenotype } & Pre-frail (1-2 criteria) & $13(39)$ \\
\hline & Frail ( $3-5$ criteria) & $18(55)$ \\
\hline \multicolumn{3}{|l|}{ Geriatric conditions } \\
\hline Falls & None & $13(39)$ \\
\hline \multirow[t]{4}{*}{ Falls in the past 12 months } & Falls & $20(61)$ \\
\hline & 1-3 falls & $11(33)$ \\
\hline & $4-7$ falls & $6(18)$ \\
\hline & $\geq 8$ falls & $3(9)$ \\
\hline Fragility fracture risk ${ }^{*}$ & Low risk ( $<5 \%$ probability) & $9 / 31(29)$ \\
\hline \multirow[t]{2}{*}{ Ten-year probability of major osteoporotic fracture } & Moderate risk (5-10\% probability) & $12 / 31(39)$ \\
\hline & High risk (>10\% probability) & 10/31 (32) \\
\hline Visual impairment & Snellen chart $<20 / 40$ & $20(61)$ \\
\hline Low grip strength & Max strength in lowest $20 \%$ for sex in ELSA data & $20(61)$ \\
\hline Mobility impairment & Self-reported & $17(52)$ \\
\hline Cognitive impairment & RUDAS score $\leq 22$ & $15(45)$ \\
\hline Malnutrition: high risk & MUST score $\geq 2$ & $13(39)$ \\
\hline Balance impairment & Self-reported & $11(33)$ \\
\hline Urinary incontinence & ISIQ-UI score $\geq 4$ & $10(30)$ \\
\hline Orthostatic hypotension & $\geq 20 \mathrm{mmHg}$ fall in systolic BP on standing & $9 / 29(31)$ \\
\hline Social isolation & Self-reported, no friends or contact with family & $10(30)$ \\
\hline Hearing impairment & Self-reported & $3(9)$ \\
\hline \multirow[t]{2}{*}{ Functional impairment } & Self-reported difficulty with one or more ADL & $6(18)$ \\
\hline & Self-reported difficulty with one or more IADL & $31(94)$ \\
\hline \multicolumn{3}{|l|}{ Multimorbidity } \\
\hline & Mean (SD) number of conditions & $7.2(2.7)$ \\
\hline \multirow[t]{2}{*}{ HSE coded LTCs (Table A2) } & Minimum-Maximum & $2-14$ \\
\hline & Participants with $\geq 2$ chronic conditions & $33(100)$ \\
\hline Depression & No depression (score $<5$ ) & $10(30)$ \\
\hline \multirow[t]{3}{*}{ PHQ-9 score } & Depression & $23(70)$ \\
\hline & Mild (score 5-9) & $9(27)$ \\
\hline & Moderate/severe (score $\geq 10$ ) & $14(42)$ \\
\hline Traumatic head injuries & None & $12(36)$ \\
\hline \multirow[t]{3}{*}{ Serious head injuries leading to loss of consciousness } & Head injuries & $21(64)$ \\
\hline & $1-2$ in lifetime & $12(36)$ \\
\hline & $\geq 3$ in lifetime & $9(27)$ \\
\hline
\end{tabular}

disease and small bowel complaints in 79\%; mental illness, serious anxiety or depression in $73 \%$; epilepsy or seizures in 55\%; visual problems in 55\%; infectious diseases (HIV, TB and Hepatitis B and C) in 45\%; hypertension in 42\%; and emphysema in $30 \%$. A full list is given in Table A2. Of all, 64\% of participants reported a history of traumatic head injury resulting in loss of consciousness, with $27 \%$ reporting three or more in their lifetime.

\section{Discussion}

This study found high prevalence of frailty and geriatric conditions in residents of a hostel in London for single PEH, comparable to residents of care homes for older people. Of these, $55 \%$ were frail and frailty scores among the participants with an average age of 56 years were comparable to 89 -year-olds in the general population. The hostel accommodated people with complex needs over the age of 30 , so included a slightly older cohort than some other hostels, but the extent of multimorbidity far exceeded the average for even the oldest people in the general population (Marshall and Higgins, 2012). In spite of the medical services available in this hostel (most hostels in the UK do not have such services) many health needs were unmet. Functional 


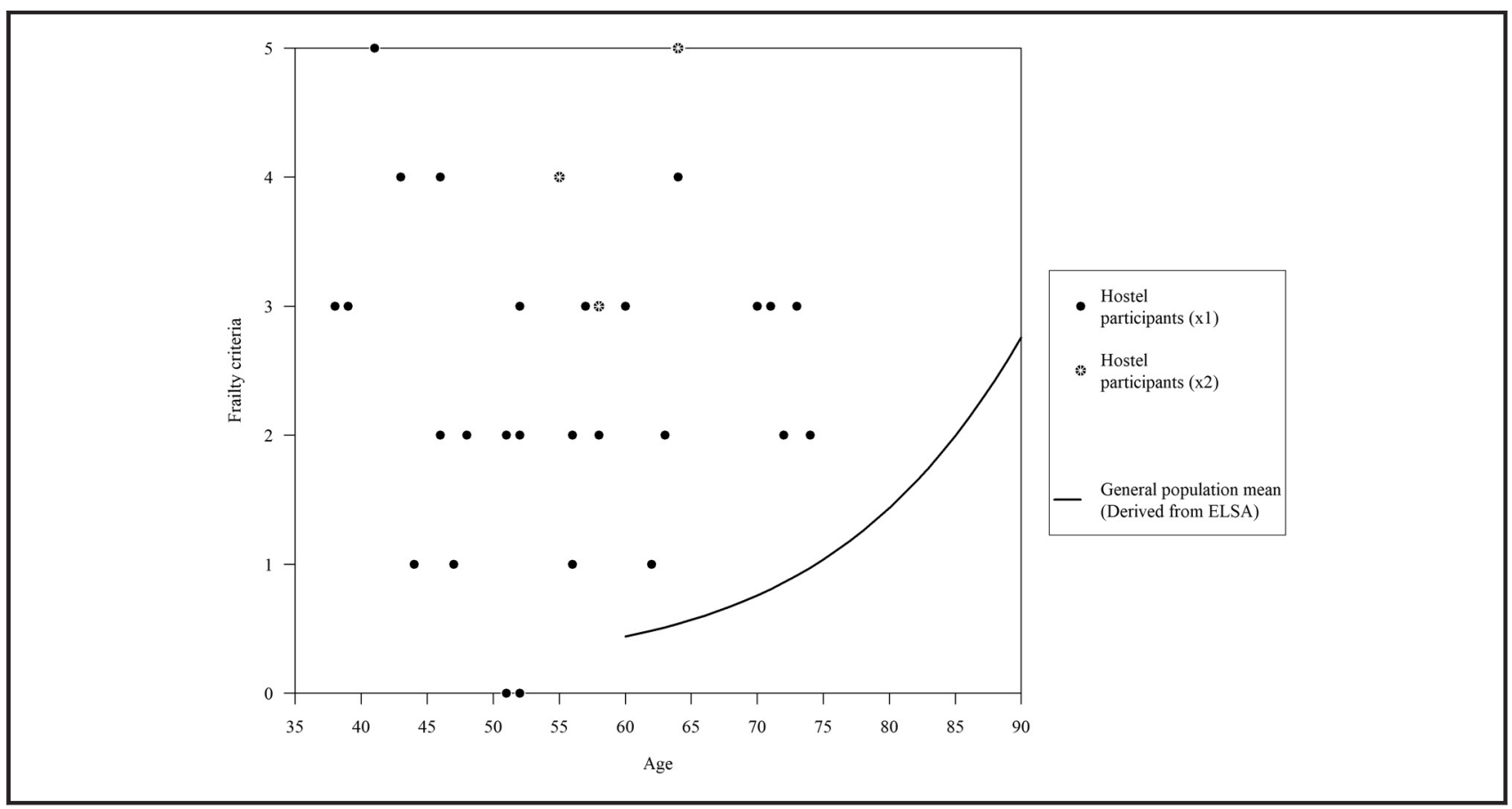

Figure 2 Multimorbidity

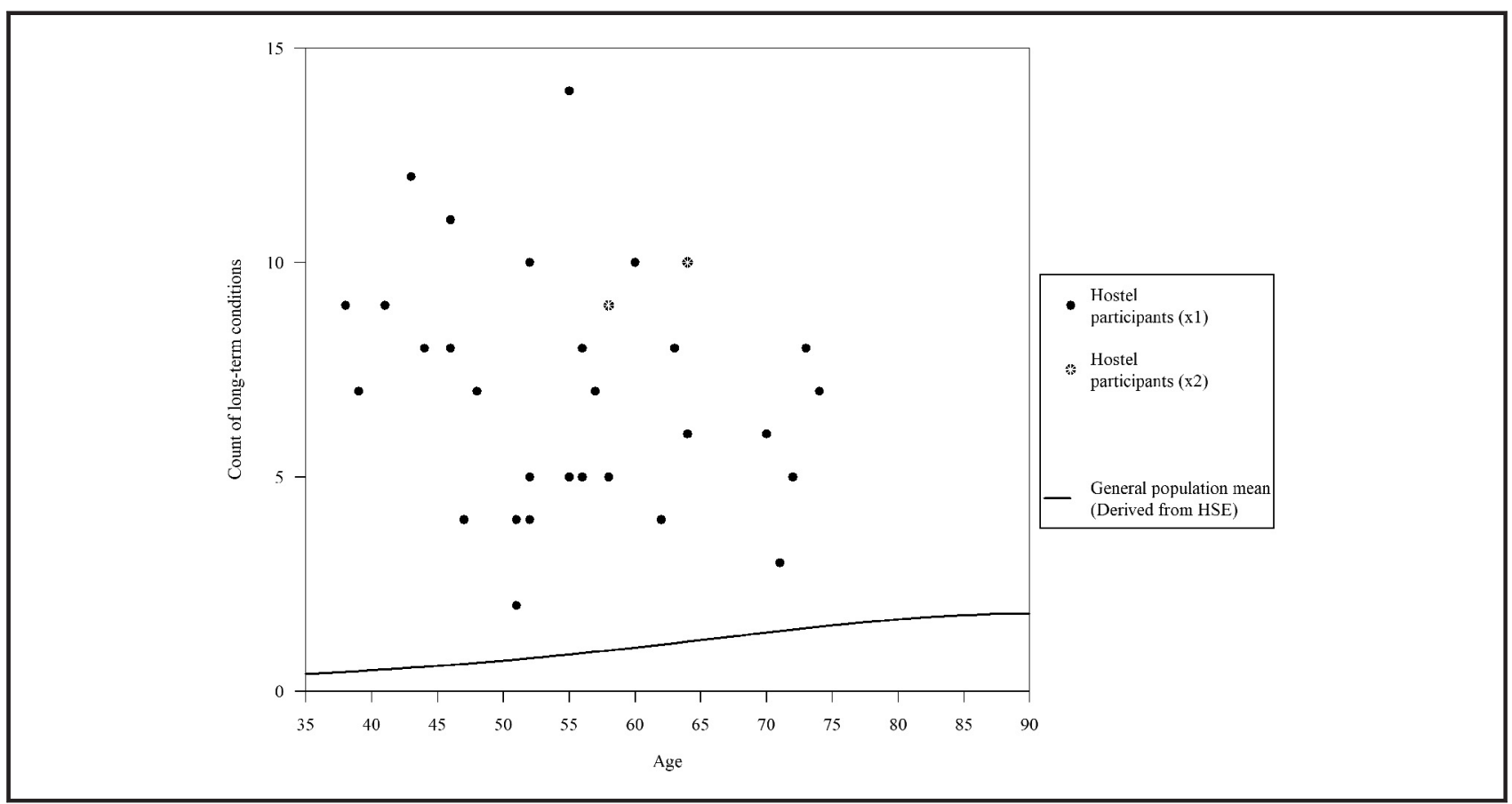

VOL. 23 NO. 3/4 $2020 \mid$ HOUSING, CARE AND SUPPORT $\mid$ PAGE 83 
assistance and personal care packages were rarely provided, with non-clinical key workers being the primary source of support for residents with extensive multimorbidity and high degrees of complexity and vulnerability.

\section{Strengths and limitations}

We achieved a high response rate (83\% of eligible residents) through flexibility with the structure and timing of interviews and gaining support from hostel staff, demonstrating the feasibility of a CGA-type evaluation in this context. We used robust assessment tools for geriatric conditions and improved the sensitivity of reported LTCs using collateral information from key workers. Participant-reported functional impairments may represent an underestimation of need, since self-assessment by homeless adults has been shown to under-identify impairments (Rodriguez-Guzman et al., 2016). This highlights the importance of collateral information, but functional abilities should ideally be directly assessed.

The main limitation is the small sample size. We focussed on a detailed assessment of a specific population rather than achieving a large sample, meaning we were unable to analyse associations between geriatric conditions and participant characteristics (such as duration of homelessness) or estimate the prevalence of conditions with precision. While it is not possible to generalise the results to the wider homeless population, all residents had a local connection to the borough and participant characteristics are similar to other surveys of PEH (Homeless Link, 2014; Bowen et al., 2019). Therefore, boroughs with ageing populations of people who are homeless are likely to have people living in hostels or other forms of temporary accommodation with equivalent need.

\section{Comparison with existing literature}

$\mathrm{PEH}$ are underrepresented and excluded from many aspects of society and research is no exception. To our knowledge, this is the first UK-based study examining frailty and geriatric conditions among PEH and the first anywhere to do so within a CGA-type evaluation. The studies of frailty and geriatric conditions in homeless populations in the USA reported comparable prevalence data (Salem et al., 2013, 2014; Hadenfeldt et al., 2017; Salem et al., 2019). Other studies also report high rates of multimorbidity associated with homelessness, but direct comparison of number of LTCs is difficult because of different classification and assessment methods (Queen et al., 2017; Bowen et al., 2019).

\section{Implications for practice}

This study reveals unmet health and care needs, some of which have been previously described (Crane and Joly, 2014; Shulman et al., 2018; Eavis, 2018; Manthorpe et al., 2019). Hostels are intended to provide short-term temporary accommodation before residents move onto more independent living, but a lack of access to sheltered housing or residential or nursing home placements, particularly in the context of drug or alcohol use, leads to many people staying for years (Table 1). This has implications for health and social care provision in hostels; the fact that many participants had difficulty with ADLs and IADLs but only $9 \%$ had support from a care package demonstrates a need to improve access to Care Act 2014 assessments (Cornes et al., 2016).

The study highlights an urgent need to assess frailty and consider geriatric conditions in $\mathrm{PEH}$ at a younger age than in the general population. Primary care guidance for managing older people with frailty states that patients should be targeted for CGA, prioritised for management of multimorbidity and have opportunities to consider advance care planning including appropriate place of care (Turner and Clegg, 2014; British Geriatrics Society, 2015; Ellis et al., 2017). This proactive patient-centred approach is lacking in the majority of encounters with mainstream services for this patient group, which frequently takes the form 
of crisis-driven hospital attendances (Bradley, 2018; Eavis, 2018; Bowen et al., 2019; Martineau et al., 2019). Primary care has a vital role in addressing this inequity. In hostels such as this, where there is primary care in-reach, there are opportunities to be more proactive, incorporating frailty assessments and CGA into consultations. Input from geriatricians and multi-disciplinary team members with experience of working with older people may also improve care where there is evidence of premature ageing and involvement should be based on clinical need rather than age.

In hostels without in-reach primary care, residents with complex needs often experience significant barriers in accessing mainstream primary care services for a number of reasons (Bradley, 2018; Eavis, 2018). Clinical commissioning groups and primary care networks should consider how to address these unmet needs and ensure their provision is inclusive and reaching this marginalised vulnerable group. Obtaining accurate functional assessments for $\mathrm{PEH}$ and frailty is essential to ensure they receive the support they are entitled to under the 2014 Care Act (Cornes et al., 2016; Martineau et al., 2019). Good practice might include frailty assessment by hostel staff followed by CGA-type evaluation in selected residents by a GP and other health-care professionals. Selected patients should have care coordinators assigned as recommended for elderly patients, with cases reviewed in wider multi-agency meetings that include housing and social care services (Turner and Clegg, 2014; British Geriatrics Society, 2015).

Quantifying multiple needs using a CGA-type process borrowed from principles used in geriatric medicine will be of practical interest to health and social care professionals who work with $\mathrm{PEH}$ and other forms of social exclusion. The process informs person-centred care planning and can help advocate for appropriate support for people with signs of premature ageing, frailty or multiple complex needs (Turner and Clegg, 2014; Ellis et al., 2017). The appropriate frailty scale to use in an assessment depends on the setting and purpose. The Fried phenotype is commonly used in research and most easily compared to population data, but is less practical for routine clinical use, as it requires time-consuming physical assessments that must be replicated accurately. The Rockwood scale relies heavily on appraisal of physical functional abilities (often preserved in younger people with frailty, who have experienced homelessness) and accounts less for other aspects of frailty, potentially resulting in lower sensitivity for frailty identification in this group. We recommend the Edmonton frail scale for use with homeless patients, particularly in a hostel or equivalent community setting, because it can be administered by non-clinical staff and has the advantage of highlighting specific areas for intervention in subsequent care plans (Rolfson et al., 2006). It is important to note that no frailty scale has yet been validated for younger populations, but our findings and experience suggest they are of real value. More research and larger studies are needed to evaluate frailty scales in inclusion health populations and others at risk of premature ageing.

\section{Conclusions}

$\mathrm{PEH}$ are at high risk of premature frailty and geriatric conditions alongside complex multimorbidity. A needs-based rather than age-based approach is essential for appropriate assessment of this population to reduce health inequities. Frailty assessment represents a useful and feasible method for identifying and targeting people for holistic person-centred care and support.

Funding: While the study received no direct funding, Briony F. Hudson used $£ 330$ to purchase supermarket vouchers for the study, using funds from a UCL Excellence in Health Research Award she had previously been awarded and an additional £2000 from this award to contribute to publication costs. The lead author Raphael Rogans-Watson received no funding. Caroline Shulman, Megan Armstrong and Briony F. Hudson are funded by a grant from The Oak Foundation (OCAY-14-574), and Dan Lewer is funded by National 
Institute for Health Research (NIHR), (DRF-2018-11-ST2-016). Both grants were awarded prior to the conception of this study and neither organisation had any role in the design, execution, analysis and interpretation of data or writing of the study, and the views expressed are those of the authors alone and do not necessarily reflect the views of either organisation. All five authors had full access to all of the data (including statistical reports and tables) in the study and can take responsibility for the integrity of the data and the accuracy of the data analysis.

Ethical Approval: The study was approved by the University College London Research Ethics Committee (ID: 6202/003). All participants provided informed consent before taking part.

Competing interests: All authors declare no competing interests, no support from any organisation for the submitted work, no financial relationships with any organisations that might have an interest in the submitted work in the previous three years and no other relationships or activities that could appear to have influenced the submitted work.

\section{References}

Avery, K., Donovan, J., Peters, T.J., Shaw, C., Gotoh, M. and Abrams, P. (2004), "ICIQ: a brief and robust measure for evaluating the symptoms and impact of urinary incontinence", Neurourology and Urodynamics, Vol. 23 No. 4, pp. 322-330, available at: https://iciq.net/wp-content/uploads/2019/08/ Sample-ICIQ-UI-Short-Form.pdf (accessed 1 October 2018)

Banks, J., Blake, M., Clemens, S., Marmot, M., Nazroo, J., Oldfield, Z., Oskala, A., Phelps, A., Rogers, N. and Steptoe, A. (2018), "English Longitudinal Study of Ageing: waves 0-8, 1998-2017", [data collection], 30th Edition, UK Data Service. SN: 5050. 2019, available at: https://beta.ukdataservice.ac.uk/ datacatalogue/studies/study?id=5050 (accessed 14 August 2019).

Bowen, M., Marwick, S., Marshall, T., Saunders, K., Burwood, S., Yahyouche, A., Stewart, D. and Paudyal, V. (2019), "Multimorbidity and emergency department visits by a homeless population: a database study in specialist general practice", British Journal of General Practice, Vol. 69 No. 685, pp. e515-e525.

Bradley, J. (2018), Health of homelessness. BMJ Rapid response to: Adebowale V, 2018. There is no excuse for homelessness in Britain in 2018. British Medical Journal, February 26;360, p. k902.

Bramley, G. (2017), "Homelessness projections: core homelessness in Great Britain", Summary report. London: crisis, available at: www.crisis.org.uk/media/237582/crisis_homelessness_projections_2017. pdf (accessed 10 August 2019).

British Association for Parenteral and Enteral Nutrition (2003), "Malnutrition universal screening tool", available at: www.bapen.org.uk/pdfs/must/must_full.pdf (accessed 4 October 2018).

British Geriatrics Society (2015), "Fit for frailty - part 2: developing, commissioning and managing services for people living with frailty in community settings", available at: www.bgs.org.uk/sites/default/ files/content/resources/files/2018-05-23/fff2_full.pdf (accessed 4 July 2018).

Brown, R.T., Kiely, D.K., Bharel, M. and Mitchell, S.L. (2012), "Geriatric syndromes in older homeless adults", Journal of General Internal Medicine, Vol. 27 No. 1, pp. 16-22.

Brown, R.T., Hemati, K., Riley, E.D., Lee, C.T., Ponath, C., Tieu, L., Guzman, D. and Kushel, M.B. (2017), "Geriatric conditions in a population-based sample of older homeless adults", The Gerontologist, Vol. 57 No. 4, pp. 757-766.

Centre for Policy on Ageing (2017), "Diversity in older age - older homelessness. rapid review", available at: www.cpa.org.uk/information/reviews/CPA-Rapid-Review-Diversity-in-Older-Age-Older-Homeless-People.pdf (accessed 10 August 2019).

Cornes, M., Ornelas, B., Bennett, B., Meakin, A., Mason, K., Fuller, J. and Manthorpe, J. (2018), "Increasing access to Care Act 2014 assessments and personal budgets among people with experiences of homelessness and multiple exclusion: a theoretically informed case study", Housing, Care and Support, Vol. 21 No. 1, pp. 1-12, doi: 10.1108/HCS-09-2017-0022.

Crane, M. and Joly, L. (2014), "Older homeless people: increasing numbers and changing needs", Reviews in Clinical Gerontology, Vol. 24 No. 4, p. 255.

Eavis, C. (2018), "The barriers to healthcare encountered by single homeless people", Primary Health Care, Vol. 28 No. 1, p. 26. 
Ellis, G., Gardner, M., Tsiachristas, A., Langhorne, P., Burke, O., Harwood, R.H., Conroy, S.P., Kircher, T., Somme, D., Saltvedt, I. and Wald, H. (2017), "Comprehensive geriatric assessment for older adults admitted to hospital", Cochrane Database of Systematic Reviews, No. 9.

Fitzpatrick, S., Bramley, G. and Johnsen, S. (2013), "Pathways into multiple exclusion homelessness in seven UK cities", Urban Studies, Vol. 50 No. 1, pp. 148-168.

Fried, L.P., Tangen, C.M., Walston, J., Newman, A.B., Hirsch, C., Gottdiener, J., Seeman, T., Tracy, R., Kop, W.J., Burke, G. and McBurnie, M.A. (2001), "Frailty in older adults: evidence for a phenotype", The Journals of Gerontology Series A: Biological Sciences and Medical Sciences, Vol. 56 No. 3, pp. M146-M157.

Gale, C.R., Cooper, C. and Aihie Sayer, A. (2014), "Prevalence of frailty and disability: findings from the English longitudinal study of ageing”, Age and Ageing, Vol. 44 No. 1, pp. 162-165.

Gelberg, L., Linn, L.S. and Mayer-Oakes, S.A. (1990), "Differences in health status between older and younger homeless adults", Journal of the American Geriatrics Society, Vol. 38 No. 11, pp. 1220-1229.

Hadenfeldt, C.J., Darabaris, M. and Aufdenkamp, M. (2017), "Frailty assessment in patients utilizing a free clinic", Journal of Health Care for the Poor and Underserved, Vol. 28 No. 4, pp. 1423-1435.

Homeless Link (2014), "The unhealthy state of homelessness: health audit results 2014", Homeless Link, available at: www.homeless.org.uk/sites/default/files/site-attachments/The\%20unhealthy\%20state\%20of \%20homelessness\%20FINAL.pdf (accessed 14 August 2019).

IBM Corp (2017), IBM SPSS Statistics for Windows, Version 25.0. IBM Corp, Armonk, New York, NY.

Kroenke, K., Spitzer, R.L. and Williams, J.B. (2001), "The PHQ-9: validity of a brief depression severity measure", Journal of General Internal Medicine, Vol. 16 No. 9, pp. 606-613.

Lewer, D., Aldridge, R.W., Menezes, D., Sawyer, C., Zaninotto, P., Dedicoat, M., Ahmed, I., Luchenski, S., Hayward, A. and Story, A. (2019), "Health-related quality of life and prevalence of six chronic diseases in homeless and housed people: a cross-sectional study in London and Birmingham, England", BMJ Open, Vol. 9 No. 4, p. e025192.

Manthorpe, J., Samsi, K., Joly, L., Crane, M., Gage, H., Bowling, A. and Nilforooshan, R. (2019), "Service provision for older homeless people with memory problems: a mixed-methods study", Health Services and Delivery Research, Vol. 7 No. 9, pp. 1-184.

Marshall, A. and Higgins, V. (2012), "Health survey for England time series dataset, 1991-2009", [data collection]. UK Data Service SN: 7025, available at: https://beta.ukdataservice.ac.uk/datacatalogue/ studies/study?id=7025 (accessed 14 August 2019).

Martineau, S., Cornes, M., Manthorpe, J., Ornelas, B. and Fuller, J. (2019), Safeguarding, Homelessness and Rough Sleeping: An Analysis of Safeguarding Adults Reviews. 2019, NIHR Policy Research Unit in Health and Social Care Workforce, The Policy Institute, King's College London, London, doi: 10.18742/pub01-006.

Ni Cheallaigh, C. and Sears, J. (2018), "Premature ageing in the homeless population. Depaul health initiative", available at: https://ie.depaulcharity.org/sites/default/files/Depaul\%2C\%20Premature\% 20Ageing\%20Report\%20Feb\%202018_0.pdf(accessed 4 September 2018).

Office for National Statistics (2019), Deaths of Homeless People in England and Wales, ONS, available at: www.ons.gov.uk/peoplepopulationandcommunity/births deathsandmarriages/deaths/bulletins/ deathsofhomelesspeopleinenglandandwales/2018 (accessed 14 October 2019).

Queen, A.B., Lowrie, R., Richardson, J. and Williamson, A.E. (2017), "Multimorbidity, disadvantage, and patient engagement within a specialist homeless health service in the UK: an in-depth study of general practice data", BJGP Open, Vol. 1 No. 3.

R Core Team (2018), R Foundation for Statistical Computing, Vienna, available at: www. R-project.org

Rockwood, K., Song, X., MacKnight, C., Bergman, H., Hogan, D.B., McDowell, I. and Mitnitski, A. (2005), "A global clinical measure of fitness and frailty in elderly people", Canadian Medical Association Journal, Vol. 173 No. 5, pp. 489-495.

Rodriguez-Guzman, J., Maiaroto, M., DeWorsop, D.O., Hassell, C., Iheanacho, T., Mecca, A.P. and Mecca, M.C. (2016), "Utilizing a direct assessment to identify functional impairments in homeless adults", The American Journal of Geriatric Psychiatry, Vol. 24 No. 3, pp. S76-S77.

Rolfson, D.B., Majumdar, S.R., Tsuyuki, R.T., Tahir, A. and Rockwood, K. (2006), "Validity and reliability of the Edmonton frail scale", Age and Ageing, Vol. 35 No. 5, pp. 526-529. 
Salem, B.E., Brecht, M.L., Ekstrand, M.L., Faucette, M. and Nyamathi, A.M. (2019), "Correlates of physical, psychological, and social frailty among formerly incarcerated, homeless women", Health Care for Women International, Vol. 40 Nos 7/9, pp. 788-812.

Salem, B.E., Nyamathi, A., Phillips, L.R., Mentes, J.C., Sarkisian, C. and Brecht, M.L. (2014), "Development of a frailty framework among vulnerable populations", Ans. Advances in Nursing Science, Vol. 37 No. 1, pp. 70-81.

Salem, B.E., Nyamathi, A.M., Brecht, M.L., Phillips, L.R., Mentes, J.C., Sarkisian, C. and Leake, B. (2013), "Correlates of frailty among homeless adults", Western Journal of Nursing Research, Vol. 35 No. 9, pp. 1128-1152.

Shelkey, M. and Wallace, M. (2002), "Katz index of independence in activities of daily living (ADL): try this: best practices in nursing care to older adults", MedSurg Nursing, Vol. 11 No. 2, pp. 100-102, 1 April, available at: https://consultgeri.org/try-this/general-assessment/issue-2.pdf (accessed 4 October 2018).

Shulman, C., Hudson, B.F., Low, J., Hewett, N., Daley, J., Kennedy, P., Davis, S., Brophy, N., Howard, D., Vivat, B. and Stone, P. (2018), "End-of-life care for homeless people: a qualitative analysis exploring the challenges to access and provision of palliative care", Palliative Medicine, Vol. 32 No. 1, pp. 36-45.

Storey, J.E., Rowland, J.T., Conforti, D.A. and Dickson, H.G. (2004), "The Rowland universal dementia assessment scale (RUDAS): a multicultural cognitive assessment scale", International Psychogeriatrics, Vol. 16 No. 1, p. 13, Full guide, available at: www.dementia.org.au/resources/rowland-universal-dementia-assessmentscale-rudas (accessed 4 October 2018).

Sullivan, G., Dumenci, L., Burnam, A. and Koegel, P. (2001), "Validation of the brief instrumental functioning scale in a homeless population", Psychiatric Services, Vol. 52 No. 8, pp. 1097-1099.

Turner, G. and Clegg, A. (2014), "Best practice guidelines for the management of frailty: a British geriatrics society, age UK and royal college of general practitioners report", Age and Ageing, Vol. 43 No. 6, pp. 744-747.

\section{Further reading}

Banks, J. Blake, M. Clemens, S. Marmot, M. Nazroo, J. Oldfield, Z. Oskala, A. Phelps, A. Rogers, N. and Steptoe, A. (2018), English Longitudinal Study of Ageing: waves 0-8, 1998-2017.[data collection], 30th Edition, UK Data Service. SN: 5050. 2019, available at: https://beta.ukdataservice.ac.uk/datacatalogue/ studies/study?id=5050 (accessed 14 August 2019).

Centre for Metabolic Bone Diseases, University of Sheffield (2008), "Fracture risk assessment tool", available at: www. sheffield.ac.uk/FRAX/tool.aspx (accessed 19 September 2018).

\section{Author affiliations}

Raphael Rogans-Watson is based at the Croydon University Hospital, Croydon, UK and Pathway, London, UK.

Caroline Shulman is based at the Marie Curie Palliative Care Research Department, Division of Psychiatry, University College London, London, UK, and Pathway, London, UK.

Dan Lewer is based at the Department of Epidemiology and Public Health, University College London, London, UK.

Megan Armstrong and Briony F. Hudson are both based at the Marie Curie Palliative Care Research Department, Division of Psychiatry, University College London, London, UK and Pathway, London, UK. 


\section{Appendix}

\section{Table A1 Frailty phenotype measurements}

\begin{tabular}{|c|c|c|}
\hline Frailty criteria & Method & Positive result \\
\hline Weakness & $\begin{array}{l}\text { Assessed with a grip strength dynamometer } \\
\text { in the dominant hand, with the maximum of } \\
\text { three attempts taken }\end{array}$ & $\begin{array}{l}\text { Participants were judged to have weakness } \\
\text { if maximum strength was in the lowest } 20 \% \\
\text { of the distribution for their sex from the } \\
\text { general population reference data from } \\
\text { ELSA }\end{array}$ \\
\hline Slow walking speed & $\begin{array}{l}\text { Timed-up-and-go (TUG) test (participants } \\
\text { instructed to stand from a seated position, } \\
\text { walk } 3 \mathrm{~m} \text {, turn around, walk back and return } \\
\text { to a seated position) }\end{array}$ & $\begin{array}{l}\text { Slow speed defined as TUG greater than } 12 \\
\text { s or an inability to walk }\end{array}$ \\
\hline Unintentional weight loss & Height and weight measured & $\begin{array}{l}\mathrm{BMI}<18.5 \text { or }>4.5 \mathrm{~kg} / 5 \% \text { weight loss in } 1 \\
\text { year compared to previous weight or self- } \\
\text { reported }>4.5 \mathrm{~kg} / 5 \% \text { weight loss in } 1 \text { year if } \\
\text { no previous weight documented }\end{array}$ \\
\hline Exhaustion & $\begin{array}{l}\text { Asked "in the past } 6 \text { months, how often do } \\
\text { you feel fatigued or exhausted?" }\end{array}$ & $\begin{array}{l}\text { Answered "most of the time" } \\
\text { Other negative options were "not at all", } \\
\text { "rarely" and "some of the time" }\end{array}$ \\
\hline Low physical activity & $\begin{array}{l}\text { Asked "in the past } 30 \text { days, how often have } \\
\text { you done physical activity for more than } 10 \\
\text { minutes at a time?" Answered for mild, } \\
\text { moderate and vigorous activity }\end{array}$ & $\begin{array}{l}\text { Answered "hardly ever" for both moderate } \\
\text { and vigorous activities } \\
\text { Other negative options were " } 1-3 \text { times a } \\
\text { month", " } 1 \text { to } 2 \text { times a week" and "more } \\
\text { than } 3 \text { times a week" }\end{array}$ \\
\hline
\end{tabular}


1

27

\section{4}

2

$=3$

$=3$

5

6

7

8

$=9$

$=9$

$=9$

$=9$

$=9$

$=9$

$=15$

$=15$

$=15$

$=15$

$=19$

$=19$

$=19$

$=22$

$=22$

$=22$

$=22$

$=22$

$=27$

$=27$

$=29$

$=29$

$=29$
Other digestive complaints (stomach, liver, pancreas, bile ducts, small intestine - duodenum, jejunum and ileum)

Mental illness/anxiety/depression/nerves (nes)

Epilepsy/fits/convulsions

Cataract/poor eye sight/blindness

Infectious and parasitic diseases

Hypertension/high blood pressure/blood pressure (nes)

Bronchitis/emphysema

Other endocrine/metabolic

Other problems of nervous system

Varicose veins/phlebitis in lower extremities

Other blood vessels/embolic

Stomach ulcer/abdominal hernia/rupture

Other bladder problems/incontinence

Other problems of bones/joints/muscles

Complaints of bowel/colon (large intestine, caecum,

bowel, colon and rectum)

Kidney complaints

Arthritis/rheumatism/fibrositis

Disorders of blood and blood-forming organs and immunity disorders

Cancer (neoplasm) including lumps, masses, tumours and growths and benign (non-malignant) lumps and

cysts

Other heart problems

Skin complaints

Diabetes including hyperglycaemia

Poor hearing/deafness

Stroke/cerebral haemorrhage/cerebral thrombosis

Asthma

Back problems/slipped disc/spine/neck

Heart attack/angina

Complaints of teeth/mouth/tongue

Mental handicap

Migraine/headaches

Other eye complaints

Tinnitus/noises in the ear

Meniere's disease/ear complaints causing balance

problems

Other ear complaints

Piles/haemorrhoids

Hayfever

Other respiratory complaints

Urinary tract infection

Reproductive system disorders
$26(79 \%)$

$24(73 \%)$

$18(55 \%)$

$18(55 \%)$

$15(45 \%)$

$14(42 \%)$

$10(30 \%)$

$9(27 \%)$

$8(24 \%)$

$8(24 \%)$

$8(24 \%)$

8 (24\%)

$8(24 \%)$

$8(24 \%)$

$6(18 \%)$

$6(18 \%)$

$6(18 \%)$

$6(18 \%)$

$4(12 \%)$

$4(12 \%)$

$4(12 \%)$

$3(9 \%)$

3 (9\%)

3 (9\%)

$3(9 \%)$

$3(9 \%)$

$2(6 \%)$

$2(6 \%)$

$1(3 \%)$

$1(3 \%)$

$1(3 \%)$

0

0

0

0

0

0 
Table A3 Study results for frailty using Fried frailty phenotype, the Edmonton frail scale and the Rockwood frailty scale

Frailty

All respondents $\mathrm{n}=33(\%)$

Rockwood frailty scale

Edmonton frail scale

Fried frailty phenotype

\begin{tabular}{lrrr}
\hline Not frail & $6(18)$ & $9(27)$ & $2(6)$ \\
Vulnerable/pre-frail & $11(33)$ & $6(18)$ & $13(39)$ \\
Frail & & & $18(55)$ \\
Mild & $16(48)$ & $18(55)$ & $7(21)$ \\
Moderate & $8(24)$ & $7(21)$ & $4(12)$ \\
Severe & $5(15)$ & $3(9)$ &
\end{tabular}

Table A4 Study results for modified Katz index and BIFS; participant and keyworker results

\begin{tabular}{|c|c|c|c|c|c|c|c|c|}
\hline Activity & \multicolumn{2}{|c|}{$\begin{array}{c}\text { No difficulty } \\
\text { Participants Keyworkers }\end{array}$} & \multicolumn{2}{|c|}{$\begin{array}{l}\text { Some difficulty (requires suppor } \\
\text { Participants Keyworkers }\end{array}$} & \multicolumn{2}{|c|}{$\begin{array}{l}\text { A lot of difficulty or unable } \\
\text { Participants Keyworkers }\end{array}$} & $\begin{array}{l}\text { Do not know o } \\
\text { Participants }\end{array}$ & $\begin{array}{l}\text { missing data } \\
\text { Keyworkers }\end{array}$ \\
\hline \multicolumn{9}{|c|}{$\begin{array}{l}\text { Modified Katz index for ADLs } \\
\text { Figures are number (\% of } 33 \text { participants) }\end{array}$} \\
\hline Bathe & $29(88 \%)$ & $20(61 \%)$ & 0 & $7(21 \%)$ & $4(12 \%)$ & $6(18 \%)$ & 0 & 0 \\
\hline Dress & $30(91 \%)$ & $23(70 \%)$ & $1(3 \%)$ & $8(24 \%)$ & $2(6 \%)$ & $2(6 \%)$ & 0 & 0 \\
\hline Toilet & $28(85 \%)$ & $27(82 \%)$ & $1(3 \%)$ & $2(6 \%)$ & $4(12 \%)$ & $3(9 \%)$ & 0 & $1(3)$ \\
\hline Transfer & $29(88 \%)$ & $28(85 \%)$ & $3(9 \%)$ & $4(12 \%)$ & $1(3 \%)$ & $1(3 \%)$ & 0 & 0 \\
\hline Feed & $31(94 \%)$ & $28(85 \%)$ & $2(6 \%)$ & $4(12 \%)$ & 0 & $1(3 \%)$ & 0 & 0 \\
\hline \multicolumn{9}{|l|}{ BIFS for IADLS } \\
\hline \multicolumn{9}{|c|}{ Figures are number (\% of 33 participants) } \\
\hline Take public transport & $23(70 \%)$ & $26(79 \%)$ & $6(18 \%)$ & $5(15 \%)$ & $4(12 \%)$ & $2(6 \%)$ & 0 & 0 \\
\hline Manage medications & $20(61 \%)$ & $10(30)$ & $8(24 \%)$ & $6(18 \%)$ & $5(15 \%)$ & $10(30 \%)$ & 0 & $7(21 \%)$ \\
\hline Manage money & $2(6 \%)$ & $11(33 \%)$ & $24(73 \%)$ & $13(39 \%)$ & $7(21 \%)$ & $6(18 \%)$ & 0 & $3(9 \%)$ \\
\hline Manage appointments & $12(36 \%)$ & $5(15 \%)$ & $19(58 \%)$ & $18(55 \%)$ & $2(6 \%)$ & $8(24 \%)$ & 0 & $2(6 \%)$ \\
\hline Write an email & $6(18 \%)$ & $4(12 \%)$ & $5(15 \%)$ & $12(36 \%)$ & $22(67 \%)$ & $12(36 \%)$ & 0 & $5(15 \%)$ \\
\hline Fill out application & $6(18 \%)$ & $4(12 \%)$ & $16(49 \%)$ & $13(39 \%)$ & $10(30 \%)$ & $14(42 \%)$ & $1(3 \%)$ & $2(6 \%)$ \\
\hline
\end{tabular}

\section{Corresponding author}

Raphael Rogans-Watson can be contacted at: Rafirw@gmail.com

For instructions on how to order reprints of this article, please visit our website:

www.emeraldgrouppublishing.com/licensing/reprints.htm

Or contact us for further details: permissions@emeraldinsight.com 